EDITED BY ANDREW WINTER, M.D.
No. CLXV.]
LONDON: SATURDAY, FEBRUARY 25, 1860.
[New Series.

\section{Clinital sectures}

\section{UNIVERSITY COLLEGE HOSPITAL, $\mathbf{B Y}$}

JOHN ERICHSEN, HsQ.,

PBOFESSOR OF SURGERY AND OF CLINICAC SURGERY IN UNIVERSITY COLLEOE, ETC.

LECTURE $\mathbf{I}$.

Treatarent of Varicose Veins of the Legs, and of VARICOCELE.

Gestcemen,-I am about to direct your attention to.day to the treatment of a diseaso of sufficiently common occurrence; namely, varicose veins.

Varix may occur wherever the veins of a part are subjected to pressure, and is met with most commonly in those of the lower half of the body. In the inferior extremity this is owing partly to pressure of the abdominal viscera on the inferior cava, partly to the weight of a long column of blood in the vein, partly to the pressure inflicted on the deep veins during muscular action, causing obstruction to the onward flow of the blood. The veins of the spermatic plexus also are fre. quently the seat of varicose enlargement, from causes of a similar nature.

Varicose veins of the lower extremity, in the majority of cases, do not give rise to sufficient annoyance to need operative interference. Usually, palliative treatment, such as the pressure of bandages, elastic-stockings, etc., suffices to alleviate the slight inconvenience oocasioned by the loaded state of the superficial veins. It occasionally happens, however, that this condition leads to such consequences as to produce serious interference with the bealth and comfort of the patient. In such cases palliative measures are no longer of service, and it behoves the surgeon to effect the radical cure of the varix by operation.

Operative interference, in varix of the lower extremity, may be rendered necessary by three conditions.

1. The veins being of very considersble size, and very tortuous, they may, by compressing the nerves, produce so much pain, and so great a sense of weight in the limb, that the sufferer is unable to make any exertion, being even crippled, and so far disqualified from entering the public services in a naval or military capacity.

2. When an ulcer occurs, and refuses to heal, in consequence of congestion of its capillaries, the granulations becoming codematous, and the surface sloughy and unable to cicatrise.

3. If a varicoso vein has burst, as it is called, that is to say it has opened by an extension of an ulcerating surface through its walls, an abundant, alarming, and even fatal hæmorrhage may take place.

These are the three reasons for operating in cases of varicose veins situated in the lower extremities. Surgeons, however, have generally been loth to operate in these cases, because they have dreaded the effects of exciting inflammation in the veins, which may become suppurative, and so run on to pyæmia. This danger does exist, undoubtedly, but it must be exceedingly trifling if the operation is properly conducted; for, on looking over my records, I find I have operated more than two hundred times, in this hospital, in such cases, and have never lost a patient, nor ever had a case of suppurative phlebitis or of pyæmia. The danger is slight, if the precaution of not opening the veins is followed. If the vein be opened, air is admitted into the wound, and the adhesive inflammation is not set up, but the suppurative form arises in its stead, whereby pus may get into the circulation, and pyæmia follow. Therefore, the chief object is to confine all inflammation to the adhesive kind; whilst this is present, there is no danger.
There are many modes of treatment in varix, all having one object in view-viz., that of causing occlusion of the vein by the adhesive inflammation. But, in my opinion, all measures should be avoided which include opening the vein, whether this be done by caustic or by the knife, as they are extremely dangerous, by leading to suppuration within; so, also, are those plans of treatment by which we break down the exuded lymph and coagula, or open up the vein even when occluded.

I shall not enumerate all the methods before the profession for the radical cure of varix, but proceed to describe those which I have for many years successfully employed in this hospital. The plan I ordinarily pursue, and which you have seen me adopt dozens of times, is as follows:-A hare.lip pin is passed underneath the vein on one side, and its point brought out on the other, a piece of elastic bougie, about an inch in length, is then laid over the vein parallel to its course. Then, by means of a silken thread twisted over the bougie and under the two ends of the pin, the vein is compressed between the pin and bougie. In -performing this operation, there are one or two little points to be observed. The first is to be careful not to transfix the rein with the pin; if the vein be opened, and the pin lie across it, there is danger of suppuration, as the pin acts as a kind of seton in the vein. This inadrertenco is avoided by dipping the pin deeply, whilst passing it under the vein. In this way, there is no risk of piercing the vessel. If a drop or two venous blood exude, by the side of the pin, through the puncture, the vein has been perforated, and the instrument should be withdrawn, and passed again. If the vein is unharmed, the operation is bloodless. The second point is, that the ligature should not be so tight as to canse ulceration by strangulation of the parts compressed. If the thread be moderately tight only, and the pin made, as it generally now is, of unoxidisable iron, it is quite passive, and does not rust, hence excessive irritation is avoided. The bougie and pin should remain about ten days, at the end of which time the vein is converted into an impervious cord of plastic matter and coagulum. When this is attained, the pin may be removed, the limb bandaged, and tho patient may leave his bed.

It has been objected to this and to all other operations for rarix, that the cure is not permanent; that the varicose condition is apt to return; that the same veins perhaps are not affected again in this manner, but that others speedily assume a dilated and tortuous state. No doubt this is the result in some instances, but in many cases which I have had an opportunity of exumining years afterwards, the cure has been per. manent; and, in the meantime, the object for which the operation was andertaken is served.

Another method which is much used in France, and which I have occasionally employed myself in this hospital for some years past, is that of injecting a small quantity of a solution of the perchloride of iron, of a specific st:ungth, into the veins, by means of Pravaz's screw-syringe. In this way the blood contained in the dilated vessel is made to coagulate, and thus the passage through the vessel is occluded. The adhesive inflammation at the same time being excited, permanent obstruction is attained, and a cure effected. This, though a valuable means when the vessels are knotted and sacculated, is not, I believe, so good a one as the pin and ligature, because I have seen it followed, in two or three of the cases in which I have had occasion to use it, by circumscribed abscesses, and even sloughing of the adjacent parts, though no fatal result has, as yet, occurred in my practice. On this account, I consider this mode of treatment undoubtedly more dangerous; and I think it ought to be confined to the cure of those cases only where the knots are so large, and so closely matted together, that the pin cannot be passed underneath them.

The next distribution of reins liable to varix is that formed by the spermatic plexus. Dilatation of these vessels-rarico. cele-is often met with in young men; and much benefit can be afforded by palliative means, such as supporting or compressing the tumour in various ways; for instance, by raising the scrotum in a suspensory bandage, or by wearing a moo- 
main truss, etc., and one or other of these contrivances generally gives sufficient relief for the patient's comfort. But I have found it necessary to have recourse to more active measures than these, and to adopt operative treatment in three of the cases which have presented themselves during the present session. The circumstances for which operation may be and has been practised, in these and similar cases, can be arranged in the four following categories:-

1. The existence of a varicocele disqualifies the sufferer from admission into the public services. This, in my opinion, is a perfectly legitimate reason for operating. One of the cases on whom I recently effected a radical cure, was that of a man in the prime of life, who, wishing to enlist in the Marines, was refused solely on the ground of having a small varicocele. This I cured by operation, and the man afterwards entered the service.

2. In cases in which the presence of a varicocele of inordinate size causes a distressing sense of weight and pain in the loins and groins, and often inability to stand or walk for any length of time, in these cases, when the patient is in continual discomfort, or more or less prevented from pursuing his ordinary avocations, in fact, quite crippled, it is perfectly justifiable to resort to operation.

3 . When atrophy of the testicle is a consequence of the pressure of the blood in the veins.

4. In cases, also, where the pressure of the enlarged veins on the spermatic nerves produces repeated attacks of spermatorrhoea; and these cases, gentlemen, are by no means uncommon. These are, however, more frequently met with out of the hospital than in individuals of the class who apply to such institutions for relief. In fact, young men of the more highly educated classes are very subject to it, especially those who habitually lead a sedentary and studious life, as, for instance, young clergymen and lawyers. In these persons a peculiarly hypochondriacal state is brought on by the tendency of the mind to dwell on the condition of the genital organs, and the patient is constantly fidgetting about the local and tangible disease be observes in them. This was the case in the patient on whom you recollect I operated a short time ago for double varicocele, and who has received a better education than most hospital patients, for he belongs, in some degree, to the medical profession. His anxiety with regard to this disease, though the veins affected have been perfectly occluded by the method presently to be described, is still so great that, at his earnest importunity, I removed, last week, a portion of the scrotum which happened to be rather more pendulons than is usual, partly in order better to support the testis, and partly that his morbid feeling on this subject might in some degree be assuaged.

Now, how should the radical cure of this condition be produced? To this I would answer-By exciting adhesive inflam. mation of the spermatic veins, through an application of the same principle which sets up that process in the veins of the lower extremity. There are several different ways of doing this; some are very objectionable. The twisted suture, as applied to the veins of the leg, induces too great irritation in the scrotum, and there its introauction is often followed by violent inflarnmation or sloughing, or by an opening up of the cellular tissue of the scrotum with œdema, and even purulent infiltration. It is better, I think, not to use this method here, indeed $I$ have twice, in the practice of others, seen it followed by death. The plan I have adopted for some years, is that suggested and practised by Vidal, a distinguished French surgeon, and is as follows:-The vas deferens, readily distinguished by its round cord-like feel, is first separated from the veins, and entrusted to an assistant; next an iron pin, bored with a hole at each end, is passed between the vas and the veins, and brought out, first notching the scrotum with a scalpel at the point of perforation; then a silver-wire, threaded on a needle so constructed that the wire shall follow it without catching, is passed in at the aperture of entry of the needle, and then carried between the integument of the scrotum and the veins, the wire is brought out at the second puncture. Each end of the wire is now passed through the corresponding hole of the pin, which is twisted round and round repeatedly, each turn causing the wire to be rolled around the pin, and so tightened till the veins are firmly compressed between the pin behind and the loop of wire in front. By this means the scrotum is quite free and uncompressed, and there is no danger of arousing inflammation or œedema. The wire should be tightened from day to day, as it causes ulceration in the veins until it has completely cut through, which results, usually, in about a week or ten days. Meanwhile there is much plastic matter thrown out around the veins, this finally contracts, and obliterates their channels. This method is an effectual and permanent cure, as we had an opportunity of seeing in the case of a porter at this hospital, on whom I performed this operation with perfect success, for he remained here for three years after the operation, during which time he was perfectly free from any return of his disease. Of late, I have been in the habit of employing a simpler method, one which you saw me adopt about ten days or a fortnight ago. I separated the vas in the usual way, and then made a small incision, about half an inch long, in the front and back of the scrotum, afterwards passing a needle armed with silver-wire, as before described, between the vas and the veins, bringing it out behind, then returning the needle, but this time carrying it in front, between the veins and the skin, and so including the veins in a loop of wire, without implicating the scrotum. This is then tightly twisted together, so as to constrict the inclosed vessels. This plan had a similar effect to that of the wire and pin combined; by repeated tightening the wire gradually effected a passage, by ulceratian, through the veins, which were obliterated by the same process.

It has been objected to this and similar operations, that atrophy of the testis may take place from its arterial branches being included together with the veins, but as the spermatic artery runs near to the vas deferens, and is held out of the way with that duct, it escapes, and the chance of that mischief is avoided. Nevertheless, atrophy of the testis may coexist, as the result of long-continued pressure of the blood in the vessels of the gland before the operation was performed.

\section{yacation a a}

\section{FIBRINOUS DEPOSITION IN} THE HEART:

ITS HISTORY AND PRACTICAL MEANING.

DELIVERED AT THE GROSVENOR PLACE SCHOOL OF MEDICINE.

By BENJAMIN w. RICHARDSON, M.A., M.D., M.R.C.P., Jecturer on Physiology at the School, and Senior

Physician to the Royal Infirmary for

Diseases of the Chest.

\section{LECTURE II.}

Conditions of Disease in which Deposition of Fibrine occur's in the Heart: Symptoms and Diagnosis of Concretion.

$$
\text { [Concluded from } p .125 .]
$$

THE symptoms of concretion on the right side of the heart, in their unmixed character, are sufficiently clear. I know of nono more submissive to calm and considerate diagnostic skill. It is to be admitted, at the same time, that when complicated with other symptoms, these symptoms being developed in an important organ, as the lung, the diagnosis is much more obscure. In such a disease as croup, this embarrassment is markedly brought out; for the mind has to balance between those symptoms which are due to the withholding of air from the lungs, and those which are incident to suppression of blood. In such cases, physical examination best avails. If, then, such examination shows that there is distinct and persistent obstruction to the passage of air along the windpipe; if the lungs give evidence of congestion ; if the action of the heart be free and regular,the inference to be drawn is that, whatever may be in the heart, the leading indications point to the windpipe as the seat of the most important change: and this inference will be doubly strengthened if, in addition to the physical demonstrations above suggested, there be spasmodic dyspnœa instead of gasping dyspncea; blueness or bronzed state of the skin, instead of ashy paleness; and convulsion, violent convulsion, instead of restless agitation and tremor.

Symptoms of the class here named may entirely mask those of concretion; and such masking may be present in any form of inflammatory affection of the organs of respiration; or the two series of symptoms - those, I mean, of inflammatory lesion of the air-passages, and those of concretion-may be blended, the one or the other prevailing by the accident, I had almost said, of prior development. I have thus found concretion present in cases of pulmonary inflammation, where $I$ have not been 